\title{
Inter-University Bibliometric Comparison of Research Output within Engineering Departments: A Small-Scale Case Study at the University of Central Florida and the University of Miami
}

\section{Mr. James Sobczak, University of Miami}

James graduated with a Master of Library and Information Science from the University of Washington's Information School (iSchool) in 2018. Prior to this, he received a Master of Architecture from Yale University in 2012 and a Bachelor of Science in Architecture from the University of Michigan in 2007. James joined the faculty of the University of Miami Libraries in the fall of 2018 as the STEM librarian and is currently a librarian assistant professor at the Otto G. Richter Library on the Coral Gables campus. His research interests currently focus on the development of information and critical literacy skills within the design and science disciplines. James also looks to explore how libraries can assist the traditional STEM fields to productively engage with art and design instruction to create a more holistic pedagogy in higher education, i.e. transforming STEM into STEAM.

\section{Mr. Buenaventura Basco, University of Central Florida}

Buenaventura (Ven) Basco is currently working as Associate University Librarian at the University of Central Florida. He is the subject librarian for the College of Engineering and Computer Science, supporting the research of faculty and developing information literary instruction programs for all students in the College.

Ven has several interests in many aspects of librarianship - STEM instruction, collaboration and outreach, international relations programs and initiatives, and diversity issues. 


\title{
Inter-University Bibliometric Comparison of Research Output within Engineering Departments: A Small-Scale Case Study at the University of Central Florida and the University of Miami
}

\begin{abstract}
Bibliometrics is a commonly used tool in the area of information science for measuring and evaluating the scholarly impact of academic researchers. While the numbers and statistics generated by bibliometric analysis are easily understood and provide standardization for comparison of research outputs, they also run the risk of being overused, oversimplified, and generally isolated from any nuance or contextual information - potentially negating more meaningful application within scientific publication practices. This study looks to better understand these bibliometric concerns through the lens of a small-scale bibliometric comparison of the faculty research output of two similar populations - the Civil, Environmental, and Construction Engineering Department at the University of Central Florida \& the Civil, Architectural, and Environmental Engineering Department at the University of Miami - through article-level bibliometrics using Web of Science ${ }^{\circledR}$ (published by Clarivate Analytics). Given the impending ramifications of global climate change, a particular interest to the residents and higher education institutions in the state of Florida, this study also takes a closer look at those publications directly and indirectly focused on topics of climate change mitigation, adaptation, or resilience. By establishing solid benchmarking criteria within this narrow band of research activity, this study could be expanded to include other similar departments at many colleges and universities. Through future projects like this one, engineering and science librarians could gain a better understanding of similar engineering research outputs within the state of Florida, identify potential areas of regional/geographic collaboration, and develop meaningful library-related services/resources to better assist these engineering researchers and faculty.
\end{abstract}




\section{introduction}

Scientometrics, as part of the larger work of bibliometrics, has been a long-standing tool for evaluating the scientific rigor, impact, and trends of scientific output at major academic and research institutions. By looking at the popularity and frequency of subject terms and journal titles in which researchers publish, it is possible to get a clearer overview of how researchers both specialize and collaborate within their field and subject area [1]. Keyword analysis, which draws on similar metadata retrieval and processing, can also provide meaningful insight into scientific publishing trends [2].

While there have been several bibliometric analyses of researcher output, there have been few studies that look at bibliometrics in terms of engineering researcher output. Some of these comparison studies either look at research output within a single institution [3]-[6], a given subject or discipline [7]-[10], or a geopolitical region [11], [12]. Only one study was identified that attempted to compare faculty publication output across different engineering schools at the department level, but this study only looked at total publication numbers and citation counts rather than subject terms [13]. There are no studies that the authors of this paper could identify that conduct a keyword or subject term comparative bibliometric analysis of engineering faculty and researcher output at similar engineering departments at two separate universities. This type of intercollegiate and interdepartmental study could offer a unique insight into identifying areas of overlap and potential collaborations between similar engineering departments in close geographic proximity. Closing this research gap has the potential to provide significant benefit, not only to the two universities in this study, but also lay the groundwork for potential processes and methods to be adopted by future bibliometric studies within the field of engineering research.

\section{institutional \& departmental profiles}

The University of Miami (UM), founded in 1925, is a private university located in the city of Coral Gables in Southeast Florida. As one of the eleven schools and colleges across its three campuses, the College of Engineering, founded in 1947, is comprised of five departments: Civil, Architectural, and Environmental Engineering; Electrical and Computer Engineering; Industrial Engineering; Mechanical and Aerospace Engineering; and Biomedical Engineering.

The University of Central Florida (UCF), founded in 1963, is one of the 11-member institutions of the State University System and located 13 miles east of downtown Orlando. The College of Engineering and Computer Science, formally organized by the Engineering faculty in the Fall of 1968, is comprised of six departments: Civil, Environmental, and Construction Engineering; Computer Science; Electrical and Computer Engineering; Industrial Engineering and Management Systems; Materials Science and Engineering; and Mechanical and Aerospace Engineering.

A summary comparison of these two Universities and their respective departments, according to information included in their America Society for Engineering Education (ASEE) 2018 profiles, is provided [14]. See Table 1. 
Table 1: University Information

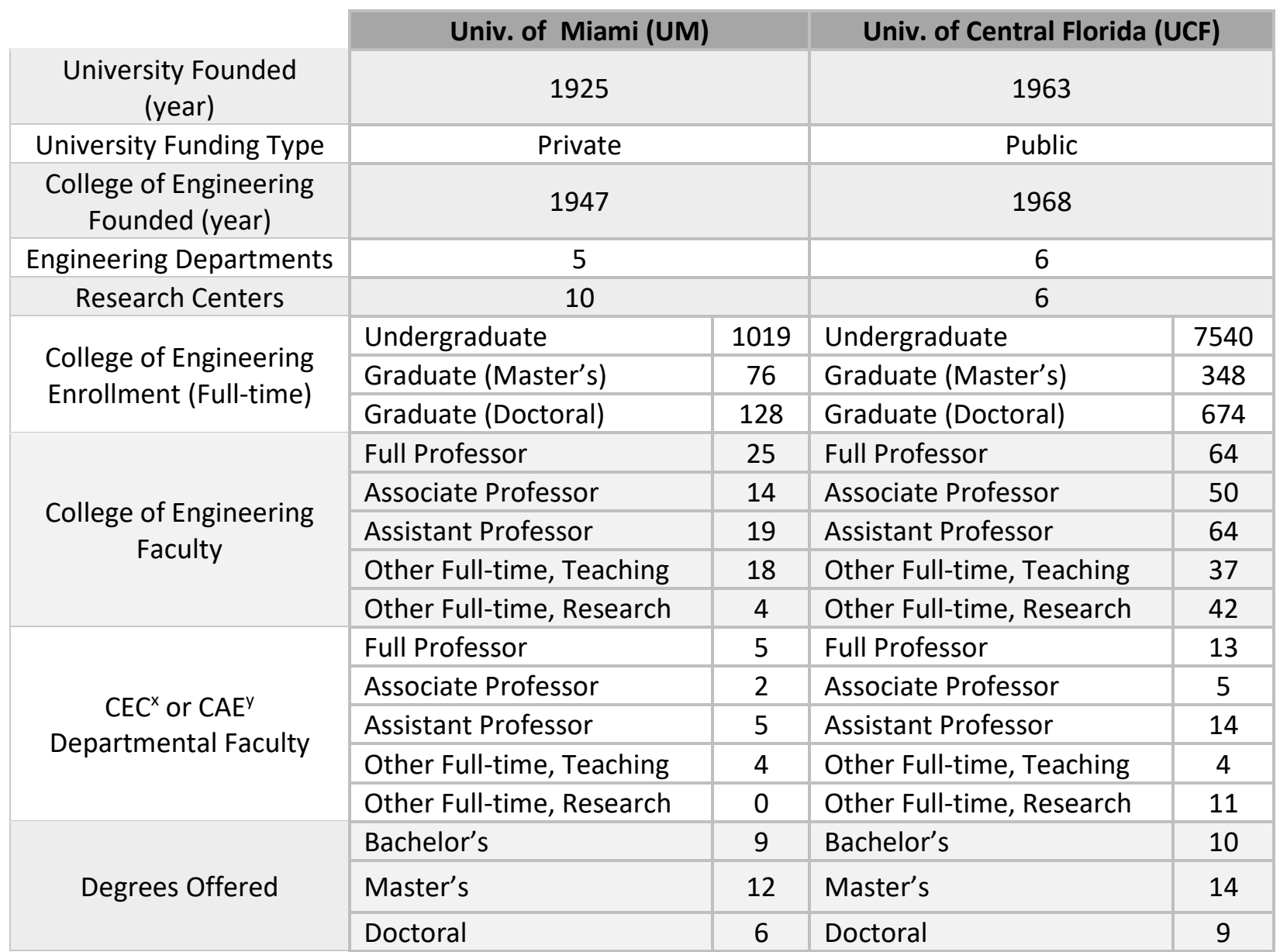

${ }^{x} \mathrm{CAC}=$ Civil, Environmental, and Construction Engineering

${ }^{y} \mathrm{CAE}=$ Civil, Architectural, and Environmental Engineering

\section{scope}

Specifically relating to faculty publications, this study looks to investigate the range, distribution, or frequency of the following:

- KeyWords Plus ${ }^{\circledR}$ keywords

- author-supplied keywords

- keywords as determined by bulk text-mining analysis of publication abstracts

- keywords as they relate to environmental concepts of "climate change"

- keywords associated with the Florida region

- journal titles in which these engineering faculty publish 


\section{methods}

To collect the corpus of scholarly output from these two groups of faculty members, the authors downloaded their complete publication records from the Web of Science ${ }^{\circledR}$ Core Collection v5.34 (hereafter referred to as WoS). According to the database's publisher, Clarivate Analytics, the WoS collection contains "the world's leading scholarly journals, books, and proceedings in the sciences, social sciences, and arts and humanities" [14]. As the goal of this study was to look holistically at research interests and scholarly outputs over entire faculty members' entire academic careers, the authors of this study included all available indexes, date ranges, and publication types available from WoS for faculty publications for inclusion within this study's data collection. Therefore, faculty publications were not limited to the time periods in which they are employed at their current institution. As a cut-off date for inclusion in this study, the authors only included faculty publications that were published before December 31, 2019.

In order to disambiguate common author name searches, this study utilized the WoS Author Search $^{\text {Beta }}$ function. This smart search function helps to better filter search results to only include those results in which metadata markers, such as known identifiers (e.g. ORCID) or current institutional/academic affiliations, all correspond to a single author [15]. This search methodology provided a total of 2732 publications (789 publications from the University of Miami and 1943 publications from the University of Central Florida) for comparison and analysis.

\section{limitations}

Other databases and indexes (e.g. SCOPUS, Compendex, etc.) were also considered as possible sources for bibliometric data. Because each of the authors of this study was required to do the bibliometric data collection for their own engineering faculty at their respective institutions, only databases to which both institutions and/or their libraries maintained active subscriptions were considered. Google Scholar, as a free and widely utilized source of bibliometric data, was also considered as a possible or primary search tool for this study. Google Scholar has been shown to provide a greater ability than some commercial databases to capture publications such as conference proceedings and non-English journal articles [17]. After several primary search exercises, the authors of this study did not have confidence that the Google Scholar results would match the same level of author disambiguation and rigorous vetting of publication results that WoS offered, and therefore chose not to utilize Google Scholar in this initial study. Because only one database was chosen, there is the possibility that some faculty publications were missed. Comparing the WoS search results across multiple databases, cross-referencing faculty-supplied curricula vitae, or utilizing institutional research management systems (RIMS), if available, could help to eliminate these gaps in the future. Still, after carefully examining the output of WoS, this study maintains a high degree of confidence that a large percentage of the total faculty output was captured and that the results of this initial study are both informative and representative of their faculty's collective scholarly output. 


\section{results and interpretations}

\section{- Web of Science Subject Categories}

In order to better understand the various subject categories in which the faculty members of UCF and UM publish, this study mapped the frequency of documents in each of the "subject categories" as defined by Web of Science. While these subject categories are defined at the publication level (e.g. journal title), rather than the document record level (e.g. journal article), they still provide a robust means of determining subject content [17]. Initial results from this analysis showed that a surprisingly large number of subject categories were included in the total publication pool. In other words, a subject category was counted if it was associated with at least one faculty member publication at either institution. Of the available 254 subject categories within WoS, 135 (53\%) were applied to faculty publications. These results were informative in mapping the sheer scope and breadth of faculty publications, showing that while these two groups of engineering faculty are certainly experts within niche subject areas, they also seemed to show a strong inclination for multidisciplinary research, even if this research was indirectly or only tangentially connected to their main research interests.

While this gives a great overall picture of the publishing landscape, it does little to show where research interests accumulate. These accumulation areas might act as fertile grounds for present and future faculty collaborations or research partnerships. To get these areas of concentrated research interest within each institutional pool of faculty members, another selection of research subject categories was generated. This subset includes only those subject categories in which $>25 \%$ of an institution's faculty members published. This reduced the initial 254 subject categories down to 29 (11\%). Mapping these results as a heat map allowed this study to visualize areas of research concentration amongst these two populations. See Table 2.

After assigning color values to this table to generate a heatmap, several interesting trends became apparent. It is not surprising that both groups of faculty members at UCF and UM have a high number of publications in the categories of construction \& building technologies; engineering; civil engineering; electrical \& electronic engineering; environmental engineering; environmental sciences; and water resources. Other portions of the heatmap show that each university had high concentrations around specific subjects. While UM had a high number of publications in materials science - composites and materials science - multidisciplinary, UCF had a high number of publications in public, environmental \& occupational health; transportation; and transportation science \& technology. It is also interesting to note that when comparing both institutions within the constraints of this 29 subject category subset, each university only has one category in which 0 publications are present as compared to the other university - materials science, coatings \& films in the case of UCF and meteorology \& atmospheric sciences in the case of UM. 
Table 2: Web of Science - Subject Categories with >25\% Faculty Participation

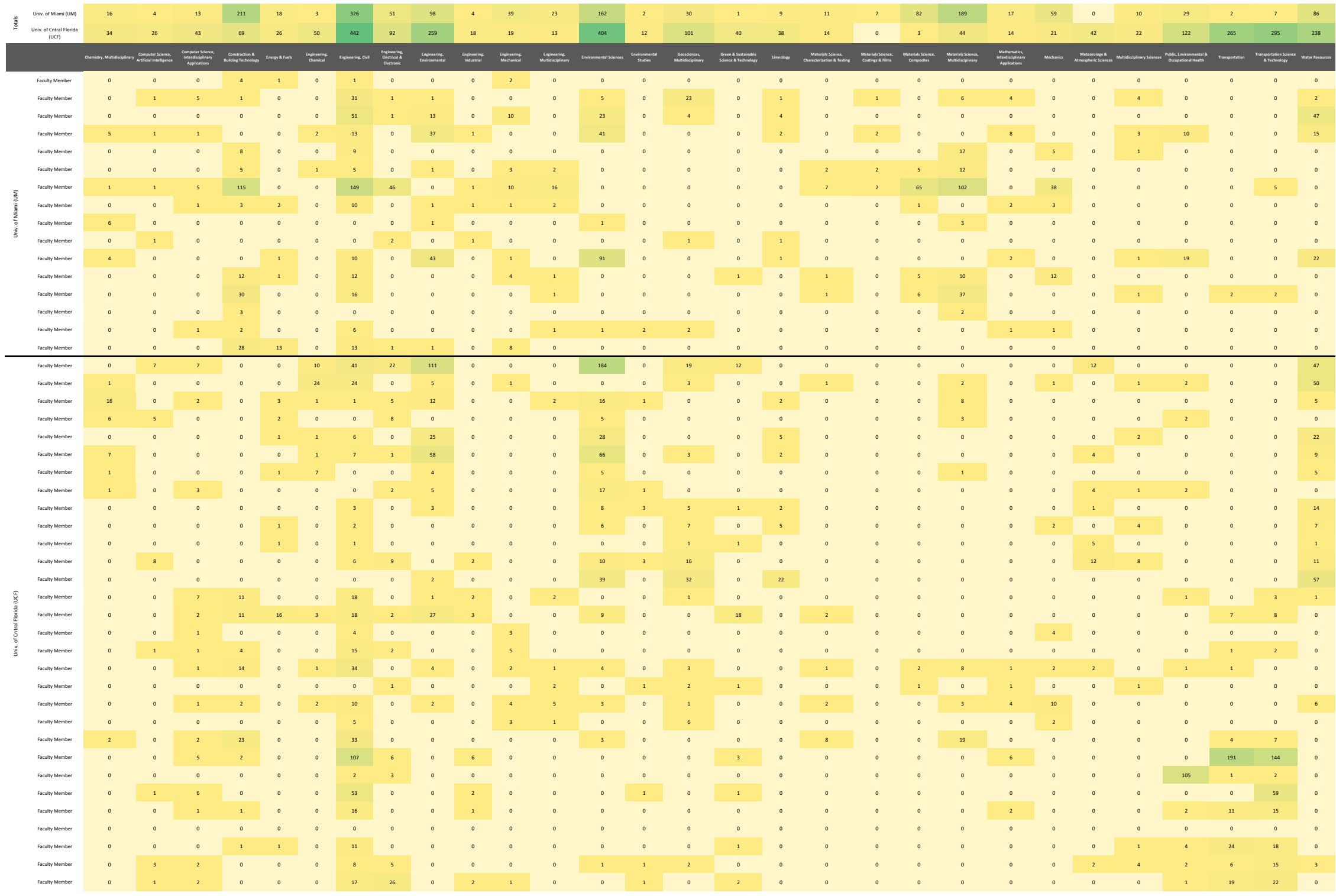


The first keyword search metric this study wanted to consider was the frequency and distribution of KeyWords Plus terms. Developed and implemented by Clarivate Analytics for their various database products starting in 1991, KeyWords Plus terms are algorithmically determined terms that: 1) "frequently appear in the titles of an article's references, but do not appear in the title of the article itself" and 2) "appear more than once in the bibliography" [18]. After compiling these KeyWords Plus terms and ranking the top twenty terms according to frequency, there are a number of terms (e.g. behaviors, performance, model, design, and water) that appear in both top twenty sets. See Table 3. While it is interesting to see this overlap, the vague and general nature of these terms (i.e. these words could apply to just about any scientific research study) does not provide much insight into special research areas or interest overlaps between these two faculty populations. It is also important to note that as KeyWords Plus terms were only developed in 1991 and not retroactively applied to publications before this year, these results are not indicative of the entire corpus of faculty publications.

Table 3: KeyWords Plus Frequency Ranking

\begin{tabular}{|c|c|c|c|}
\hline & Univ. of Miami (UM) & Univ. of Central Florida (UCF) & \\
\hline Rank & Keywords & Keywords & Rank \\
\hline 1st (tie) & escherichia-coli & model* & $1 s t$ \\
\hline 1st (tie) & concrete & systems & 2nd \\
\hline $3 r d$ & behavior & impact & $3 r d$ \\
\hline 4th & performance & management & 4th \\
\hline 5 th & model & performance & 5 th \\
\hline $6^{\text {th }}($ tie) & waste & system & 6th \\
\hline $6^{\text {th }}$ (tie) & strength & prediction & 7th \\
\hline $6^{\text {th }}$ (tie) & environment & safety & 8th \\
\hline 9th & hydration & water & 9th (tie) \\
\hline 10th & speciation & behavior & 9th (tie) \\
\hline 11th (tie) & transport & frequency & 11th \\
\hline 11th (tie) & water quality & framework & 12th \\
\hline 11th (tie) & damage & uncertainty & 13th \\
\hline 11th (tie) & design & identification & 14th (tie) \\
\hline 15th (tie) & water & flow & 14th (tie) \\
\hline 15th (tie) & systems & design & 14th (tie) \\
\hline 15th (tie) & fecal indicator bacteria & variability & 17th (tie) \\
\hline 15th (tie) & fly-ash & removal & 17th (tie) \\
\hline 15th (tie) & chromium & life-cycle assessment & 19th \\
\hline 15th (tie) & copper & severity & 20th (tie) \\
\hline & & simulation & 20th (tie) \\
\hline & & energy & 20th (tie) \\
\hline & & climate change & 20th (tie) \\
\hline
\end{tabular}


- author-supplied keywords

In an effort to find more descriptive terms for comparison, the next search metric this study wanted to consider was author-supplied keywords. This analysis could serve as a unique perspective to understand the subject matters that authors classified in their work and therefore help to capture the various "themes" of their research. While the author-supplied terms yielded more specific vocabulary, of the top 20 author-supplied keywords, there was surprisingly little overlap with water quality being the only keyword in both sets. See Table 4 . This could be due to factors ranging from non-standardization of terms, subjectivity of author emphasis on specific subjects/topics, or any number of other factors. Therefore, further study of these results, most likely in conjunction with other forms of keyword analysis, may be required before any generalizations can be made regarding potential faculty research interest overlaps.

Table 4: Author-supplied Keyword Frequency Ranking

\begin{tabular}{|l|c|}
\multicolumn{1}{|c|}{ Rank } & Univ. of Miami (UM) \\
\hline 1st & Keywords \\
\hline 2nd & reinforced concrete \\
\hline 3rd & strengthening \\
\hline 4th & concrete \\
\hline 5th (tie) & corrosion \\
\hline 5th (tie) & flexure \\
\hline 7th & arsenic \\
\hline 8th & enterococci \\
\hline 9th & repair \\
\hline 10th (tie) & design \\
\hline 10th (tie) & prestressed concrete \\
\hline 12th (tie) & bond \\
\hline 12th (tie) & strength \\
\hline 12th (tie) & reinforcement \\
\hline 12th (tie) & shear \\
\hline 16th & chromium \\
\hline 17th (tie) & acoustic emission \\
\hline 17th (tie) & water quality \\
\hline 17th (tie) & thermogravimetric analysis \\
\hline 20th (tie) & copper \\
\hline 20th (tie) & treated wood \\
\hline 20th (tie) & hydration \\
\hline 20th (tie) & beach sand \\
\hline 20th (tie) & cement paste \\
\hline & cca \\
\hline
\end{tabular}

\begin{tabular}{|c|c|}
\hline Univ. of Central Florida (UCF) & \\
\hline Keywords & Rank \\
\hline remote sensing & $1 s t$ \\
\hline solid waste management & 2nd \\
\hline climate change & $3 r d$ \\
\hline systems analysis & 4th \\
\hline optimization & 5th \\
\hline life-cycle assessment & 6th \\
\hline stormwater management & 7th \\
\hline sustainability & 8th \\
\hline machine learning & 9th \\
\hline traffic safety & 10th (tie) \\
\hline modeling & 10th (tie) \\
\hline data mining & 10th (tie) \\
\hline wastewater treatment & 13th (tie) \\
\hline water quality & 13th (tie) \\
\hline nutrient removal & 13th (tie) \\
\hline genetic programming & 13th (tie) \\
\hline sustainable development & 17th (tie) \\
\hline leachate & 17th (tie) \\
\hline China & 17th (tie) \\
\hline system dynamics & 20th (tie) \\
\hline microglia & 20th (tie) \\
\hline nanofiltration & 20th (tie) \\
\hline highway safety manual & 20th (tie) \\
\hline landfill & 20th (tie) \\
\hline environmental systems analysis & 20th (tie) \\
\hline german bight & 20th (tie) \\
\hline data fusion & 20th (tie) \\
\hline
\end{tabular}


While the author-supplied keywords provide a very thorough breakdown of the subject matter and topics covered within the publications, they are reliant on the subjective analysis of the author(s) assigning the terms. This difficulty, sometimes known as the "indexer effect," has long been known to be a problematic obstacle for bibliometric researchers [19]. To help reduce some of this conscious subjectivity, this study then wanted to see if it was possible to reduce bias by using textmining of all indexed publication abstracts to determine their subject content. Using Voyant Tools (http://www.voyant-tools.org) as the primary analysis tool, the authors compiled all of the abstracts from the WoS publications into one larger text corpus. Voyant Tools was then set to find the most frequent 20 words while ignoring its default list of stopwords, i.e. common "function words" that occur naturally in the course of writing that are not germane to most typical textual analyses [20]. As this list of stopwords was not sufficient to eliminate many words common to engineering and scientific research papers (e.g. words such as model, analysis, data, etc.) the list was greatly increased by the authors of this study after several rounds of trial searches, which unfortunately reintroduces some of the human biases this analysis originally hoped to mitigate. This searching strategy also ran into issues in that it could not identify multi-word phrases because of the lack of separating punctuation (e.g. commas, parenthesis, etc.) within the bulk abstract-sourced text uploads. And while this search methodology was an imperfect system, the results of this search exercise yielded a few common terms between the faculty publications at UCF and UM. The most interesting discovery was that the term water ranked highest on both sets of keywords. See Table 5. These keyword results appear similar to those of the KeyWords Plus analysis in that the overlapping words (e.g. design, treat*, energy) are rather value-neutral and highly generalizable. It should be stated, however, that any results or conclusions about research interest overlap, due to the search-related limitations mentioned earlier, are most likely weaker than the analyses generated from either the KeyWords Plus and author-supplied searches. 
Table 5: Abstract Keyword Frequency Ranking

\begin{tabular}{|c|c|c|c|}
\hline & Univ. of Miami (UM) & Univ. of Central Florida (UCF) & \\
\hline Rank & Keywords & Keywords & Rank \\
\hline 1st & water & water & 1st \\
\hline 2nd & concrete & crash* & 2nd \\
\hline $3 r d$ & reinforce* & traffic & $3 r d$ \\
\hline 4th & wood & waste & 4th \\
\hline 5 th & frp & safety & 5 th \\
\hline 6th & strength & management & 6th \\
\hline 7th & treat* & information & 7th \\
\hline 8th & design & environmental & 8th \\
\hline 9th & fiber & vehicle* & 9th \\
\hline 10th & cca & network & 10th \\
\hline 11th & energy & design & 11th \\
\hline 12th (tie) & arsenic & scale & 12th \\
\hline 12th (tie) & structures & surface & 13th \\
\hline 14th & materials & Florida & 14th \\
\hline 15th & beams & risk & 15th \\
\hline 16th & sand & soil & 16th \\
\hline 17th (tie) & cement & treat* & 17 th \\
\hline 17th (tie) & shear & cost & 18th \\
\hline 19th & concentrations & energy & 19th \\
\hline $20^{\text {th }}$ & beach & spatial & 20th \\
\hline
\end{tabular}

- climate change keywords

The administration at both UCF and UM have clearly expressed concern for environmental stewardship and a commitment to advancing research in climate change mitigation and resilience at both the university and engineering department level [22]-[24]. Given this commitment to environmental stewardship, the authors wanted to investigate how much of their respective faculty publications contain research focusing on these topics. Searching WoS using the exact phrase "Climate Change" and limiting the results to only the "Highly Cited" or "Hot Papers" in the subject of "Environmental Science" yielded a list of possible KeyWords Plus terms to cross-reference against the author outputs at UCF and UM. While there are other methods for determining possible "climate change"-related keywords [25], the method outlined here was in keeping with this study's other keyword analyses and search exercises. Additionally, by limiting results to only KeyWords Plus terms, there was a more uniform set of terms to consider for inclusion in search comparisons. Upon analyzing the results, UCF had a wide variety of terms represented in their faculty publications, while UM only utilized a handful of terms present and in much lower quantities. This topic warrants possible further research. See Table 6. 
Table 6: "Climate Change" Keyword Appearances

\begin{tabular}{|l|c|c|}
\hline \multicolumn{1}{|c|}{} & Univ. of Miami (UM) & Univ. of Central Florida (UCF) \\
\hline "Climate Change" Keywords & No. of Appearances & No. of Appearances \\
\hline climate change & 3 & 27 \\
\hline adaptation & 0 & 0 \\
\hline emissions & 0 & 20 \\
\hline change impacts & 0 & 0 \\
\hline conservation & 0 & 0 \\
\hline drought & 0 & 0 \\
\hline land-use & 2 & 16 \\
\hline co ${ }_{2}$ & 0 & 0 \\
\hline carbon & 0 & 11 \\
\hline resilience & 0 & 9 \\
\hline biodiversity & 0 & 0 \\
\hline elevated $\mathrm{CO}_{2}$ & 0 & 0 \\
\hline energy & 0 & 27 \\
\hline deforestation & 0 & 0 \\
\hline sea-level rise & 0 & 0 \\
\hline climate & 0 & 19 \\
\hline ecosystems & 0 & 0 \\
\hline food security & 0 & 0 \\
\hline mitigation & 0 & 0 \\
\hline global change & 0 & 0 \\
\hline & 0 & 0 \\
\hline
\end{tabular}


Given that both UCF and UM are located within the same state, the authors wanted to investigate how much of their respective faculty publications contain research focusing in or around the same geographic area. Using KeyWords Plus keywords, the authors identified several terms related to two institutions' shared geography. While UM had a wide variety of terms represented, UCF only utilized one term but with a much larger quantity. This lack in the total geographic-specific keywords for UCF is surprising and warrants possible further research. See Table 7.

Table 7: Geographic Keyword Appearances

\begin{tabular}{|l|c|c|}
\hline \multicolumn{1}{|c|}{ Keywords } & Univ. of Miami (UM) & Univ. of Central Florida (UCF) \\
\hline Florida Everglades & No. of Appearances & No. of Appearances \\
\hline South Florida & 4 & 0 \\
\hline Florida & 3 & 0 \\
\hline Florida Keys & 3 & 6 \\
\hline South Florida beach & 2 & 0 \\
\hline Florida beach & 1 & 0 \\
\hline Florida red tide & 1 & 0 \\
\hline
\end{tabular}

- journal titles

The data collected shows, unsurprisingly, that many of the most popular journal titles focused on similar topics, such as construction, environmental engineering, and water management. Still, some interesting differences did emerge. UM's journals showed a distinct focus on materials engineering ( 6 out of the top 10 journal titles focused on this area of research), while UCF's journal publications showed interest in transportation engineering ( 3 out of the top 10 journal titles focused on this area of research). See Table 8. Of the top 5 journals in which both UCF and UM publish, the major subject focuses were environmental engineering and water management, highlighting a potential research area for interdepartmental collaboration. See Table 9. 
Table 8: Top Journal Publications

\begin{tabular}{|c|c|c|c|c|c|}
\hline \multicolumn{3}{|c|}{ Univ. of Miami (UM) } & \multicolumn{3}{|c|}{ Univ. of Central Florida (UCF) } \\
\hline Rank & Journal Title & $\begin{array}{c}\text { No. of } \\
\text { Publications }\end{array}$ & Rank & Journal Title & $\begin{array}{c}\text { No. of } \\
\text { Publications }\end{array}$ \\
\hline $1 s t$ & ACI Structural Journal & 33 & $1 s t$ & $\begin{array}{l}\text { Transportation Research } \\
\text { Record }\end{array}$ & 98 \\
\hline 2nd & $\begin{array}{l}\text { Journal of Composites for } \\
\text { Construction }\end{array}$ & 29 & 2nd & $\begin{array}{l}\text { Accident Analysis and } \\
\text { Prevention }\end{array}$ & 90 \\
\hline $3 r d$ & $\begin{array}{l}\text { Construction and Building } \\
\text { Materials }\end{array}$ & 27 & $3 r d$ & Waste Management & 36 \\
\hline 4 th & ACI Materials Journal & 24 & $\begin{array}{l}4 \text { th } \\
\text { (tie) }\end{array}$ & Water Resources Research & 31 \\
\hline 5 th & $\begin{array}{l}\text { Journal of Materials in } \\
\text { Civil Engineering }\end{array}$ & 21 & $\begin{array}{l}4 \text { th } \\
\text { (tie) }\end{array}$ & $\begin{array}{l}\text { Journal of Environmental } \\
\text { Management }\end{array}$ & 31 \\
\hline 6 th & Water Research & 20 & 6 th & $\begin{array}{l}\text { Transportation Research } \\
\text { Part C-Emerging } \\
\text { Technologies }\end{array}$ & 28 \\
\hline 7th & $\begin{array}{l}\text { Environmental Science \& } \\
\text { Technology }\end{array}$ & 16 & 7th & $\begin{array}{l}\text { Sustainable Solid Waste } \\
\text { Management: A Systems } \\
\text { Engineering Approach }\end{array}$ & 26 \\
\hline $\begin{array}{l}\text { 8th } \\
\text { (tie) }\end{array}$ & $\begin{array}{l}\text { Advances in Civil } \\
\text { Engineering Materials }\end{array}$ & 14 & 8th & $\begin{array}{l}\text { American Journal of } \\
\text { Agricultural Economics }\end{array}$ & 23 \\
\hline $\begin{array}{l}\text { 8th } \\
\text { (tie) }\end{array}$ & $\begin{array}{l}\text { Journal of Environmental } \\
\text { Engineering-ASCE }\end{array}$ & 14 & 9th & Journal of Hydrology & 21 \\
\hline 10th & $\begin{array}{l}\text { Abstracts of Papers of The } \\
\text { American Chemical } \\
\text { Society }\end{array}$ & 12 & 10th & $\begin{array}{l}\text { Journal of Cleaner } \\
\text { Production }\end{array}$ & 20 \\
\hline
\end{tabular}

Table 9: Common Journal Publications

\begin{tabular}{|l|c|c|c|c|}
\hline \multicolumn{1}{|c|}{ Journal Title } & \multicolumn{2}{c|}{ UM } & \multicolumn{2}{c|}{ UCF } \\
\hline Abstracts of Papers of The American Chemical Society & Rank & $\begin{array}{c}\text { No. of } \\
\text { Publications }\end{array}$ & Rank & $\begin{array}{c}\text { No. of } \\
\text { Publications }\end{array}$ \\
\hline Environmental Science \& Technology & 7 th & 12 & 12 th & 19 \\
\hline Journal of Environmental Engineering-ASCE & 9 th & 14 & 34 th & 10 \\
\hline Waste Management & 20th & 9 & 32 th & 10 \\
\hline Water Research & 6 th & 20 & 16 th & 36 \\
\hline
\end{tabular}




\section{discussion}

Overall, the results of this scientometric study were mixed. While some overlap of keyword usage was detected, specifically from the KeyWords Plus and text-mining keyword searches, the overlapping terms in these searches were not highly descriptive regarding faculty research interests. When the keyword terms were determined by the author(s), the most frequent terms were much more descriptive but showed less commonality. It is interesting to note that the two search exercises that involved algorithmically-identified terms also correspondingly generated the less descriptive list of terms. This has implications for other types of bibliometric search exercises that engineering librarians or departmental administrations might undertake on behalf of their faculty. If these populations want to gain a better understanding of the breadth of research interests of their constituent faculty, they would be better served by either looking at the author-supplied keywords or the distribution of WoS subject categories.

It is also interesting to note the overabundance of "climate change"-related terms that showed up within the various keyword searches for UCF. These terms appeared in the abstract text-mining search, the author-supplied keyword search, as well as the KeyWords Plus search. This is not the case with UM. Despite the fact that these terms are not immediately apparent within their keyword analyses, it is well-known that UM and its respective engineering departments do value, encourage, and actively conduct extensive research on issues of sustainability and responsible environmental stewardship. This discrepancy between stated values of this institution and these results deserve additional inquiry. It simply may be the case that the requisite keywords do not appear in the types of keywords search analyses conducted in this particular study. Another possible explanation could be that articles related to change mitigation and resilience were not indexed under the WoS subject "Environmental Science." Recreating this search using other WoS subject categories such as "Engineering, Environmental" and/or "Engineering, Civil," might be informative in establishing a more productive set of results for comparison.

To increase future chances of publications for UM engineering faculty to show up within these, or similar, climate change searches, it would be worthwhile to encourage faculty members to consciously and explicitly include some germane keywords related to climate change within their author-supplied keywords. It would also behoove faculty to be wary of algorithmically-generated keywords and/or the automatic discovery and indexing of "climate change"-related keywords for their publications, even if it seems obvious that these terms should be captured from the document's title or abstract.

\section{future work}

The work conducted by the authors could continue to develop and lead to additional studies. Topics could include analysis of co-author frequency, degrees of collaboration, as well as relationship mapping amongst faculty, institutions, and grant funding organizations through the use of network analysis software (such as VOSviewer). Repeating this study to look specifically at only open access (OA) publications may also highlight meaningful trends in keyword utilization.

Expanding the search of engineering faculty publications to other data sources, such as facultysupplied CVs, Google Scholar, or RIMS could also increase the number and completeness of 
faculty publication capture. More robust text analysis tools (e.g. NVivo, Atlas.ti, etc.) could also be incorporated into future studies to more rigorously analyze this publication data for additional insights.

Furthermore, this research could be expanded to other similar engineering departments within the greater geographic region and/or the state of Florida. This increased awareness of similar research interests and expertise could facilitate more collaboration opportunities between engineering institutions, faculty, researchers, and librarians. Expanding this study could also have positive repercussions in the creation of regional research networks and expertise finding mechanisms.

\section{references}

[1] W. W. Hood and C. S. Wilson, "The literature of bibliometrics, scientometrics, and informetrics," Scientometrics, vol. 52, no. 2, p. 291, Oct. 2001, doi: 10.1023/A:1017919924342.

[2] W. Lu, X. Li, Z. Liu, and Q. Cheng, "How do author-selected keywords function semantically in scientific manuscripts?" Knowledge Organization, vol. 46, pp. 403-418, Oct. 2019, doi: 10.5771/0943-7444-2019-6.

[3] J. Bhakta and T. Bhui, "Mapping the research productivity in University of Petroleum and Energy Studies: A scientometric approach," Library Philosophy and Practice, p. 1, Dec. 2018.

[4] R. M. L. Canchumani, J. Leta, and A. M. De Figueiredo, "Scientific domains: mapping of fields of knowledge of Federal University of Rio de Janeiro," Informacao e Sociedade, vol. 27, no. 2, pp. 199-218, 2017.

[5] I. Pilčević, V. Jeremić, and D. Vujošević, "Evaluating the scientific performance of institutions within the university: An example from the University of Belgrade leading institutions," Journal of the Serbian Chemical Society, vol. 83, no. 11, pp. 1285-1295, 2018, doi: 10.2298/JSC140418054P.

[6] E. Chiware and L. Skelly, "Publishing patterns at the Cape Peninsula University of Technology," South African Journal of Science, vol. 112, no. 1-2, 2016, doi: 10.17159/sajs.2016/20140220.

[7] Z. Wu, C. Chen, Y. Cai, C. Lu, H. Wang, and T. Yu, "BIM-based visualization research in the construction industry: A network analysis," International Journal of Environmental Research and Public Health, vol. 16, no. 18, 2019, doi: 10.3390/ijerph16183473.

[8] S. Ahmed and B. Huang, "Control engineering practice in 25 years: A bibliometric overview," Control Engineering Practice, vol. 88, pp. 16-20, 2019, doi: 10.1016/j.conengprac.2019.04.004.

[9] T. O. Olawumi and D. W. M. Chan, "A scientometric review of global research on sustainability and sustainable development," Journal of Cleaner Production, vol. 183, pp. 231-250, 2018, doi: 10.1016/j.jclepro.2018.02.162.

[10] J. Pollack and D. Adler, "Emergent trends and passing fads in project management research: A scientometric analysis of changes in the field," International Journal of Project Management, vol. 33, no. 1, pp. 236-248, 2015, doi: 10.1016/j.ijproman.2014.04.011.

[11] F. G. Montoya, M. G. Montoya, J. Gómez, F. Manzano-Agugliaro, and E. AlamedaHernández, "The research on energy in Spain: A scientometric approach," Renewable and Sustainable Energy Reviews, vol. 29, pp. 173-183, 2014, doi: 10.1016/j.rser.2013.08.094. 
[12] M. Tahira, R. A. Alias, and A. Bakri, "Scientometric assessment of engineering in Malaysians universities," Scientometrics, vol. 96, no. 3, pp. 865-879, 2013, doi: 10.1007/s11192-013-0961-4.

[13] R. Dumont, M. H. Dupuis, L. Focault, M. Hiller, and M. Proulx, "Innovative approaches by Ecole Polytechnique de Montreal Library," Proceedings of the IATUL Conferences, May 2005, [Online]. Available: https://docs.lib.purdue.edu/iatul/2005/papers/9.

[14] American Society for Engineering Education, "College Online Profiles." http://profiles.asee.org/ (accessed Jan. 23, 2020).

[15] "Subscribed Databases." Web of https://apps.webofknowledge.com/select_databases.do?highlighted_tab=select_databases\& product=UA (accessed Jan. 26, 2020).

[16] "Core Collection Help - Author Search." Web of Science. https://images.webofknowledge.com/images/help/WOS/hp_author_search.html (accessed Jan. 26, 2020).

[17] L. I. Meho and K. Yang, "Impact of data sources on citation counts and rankings of LIS faculty: Web of science versus scopus and google scholar," Journal of the American Society for Information Science and Technology, vol. 58, no. 13, pp. 2105-2125, 2007, doi: 10.1002/asi.20677.

[18] "Core Collection Help - Research Areas." Web of Science. https://images.webofknowledge.com/images/help/WOS/hp_research_areas_easca.html (accessed Jan. 27, 2020).

[19] M. Callon, J. P. Courtial, and W. Turner, "Future developments," in Mapping the Dynamics of Science and Technology: Sociology of Science in the Real World. M. Callon, A. Rip, and J. Law, Eds. Springer, 1986, pp. 212-217.

[20] "KeyWords Plus generation, creation, and changes," Clarivate.com Jun. 28, 2018. https://support.clarivate.com/ScientificandAcademicResearch/s/article/KeyWords-Plusgeneration-creation-and-changes?language=en_US (accessed Jan. 26, 2020).

[21] "Stopwords." Voyant Tools Help Guide. https://voyant-tools.org/docs/\#!/guide/stopwords (accessed Jan. 30, 2020).

[22] "Climate Change Special Report," University of Miami, 2016. Accessed: Jan. 23, 2020. [Online]. Available: //climate.miami.edu/built-environment/.

[23] Z. G. Kotala and UCF Today, "UCF Sea Level Rise Expert to Help United Nations with Climate Change Report," College of Engineering \& Computer Science, Feb. 06, 2019. https://www.cecs.ucf.edu/ucf-sea-level-rise-expert-to-help-united-nations-with-climatechange-report/ (accessed Jan. 27, 2020).

[24] "Home Page," Center for Hydroscience Analysis, Modeling \& Predictive Simulations (CHAMPS). http://champs.cecs.ucf.edu/ (accessed Jan. 27, 2020).

[25] D.-Y. Kim, D.-Y. Jin, K.-J. Han, and S.-T. Park, "A comparative study on data crawling and extraction of climate change issues using machine learning technique," International Journal of Innovative Technology and Exploring Engineering, vol. 8, no. 8, pp. 1062-1066, 2019. 